\title{
PSICOANÁlisis Y GÉNERO. DECONSTRUCCIÓN CRÍTICA DE LA TEORÍA PSICOANALÍTICA Y NUEVOS ENFOQUES TEÓRICOS
}

Irene Meler

\section{Introducción}

La relación entre los desarrollos psicoanalíticos y el campo interdisciplinario de los estudios de género ha sido conflictiva y a la vez, creativa. Los escritos freudianos sobre la sexualidad femenina han revelado, al análisis feminista, los sesgos androcéntricos y sexistas del edificio teórico del psicoanálisis. Sin embargo, la transformación en las relaciones sociales entre los géneros, que constituye el proyecto de cambio social más logrado durante la Modernidad, siempre necesitó el recurso a una teoría de la subjetividad. No hay, en efecto, posibilidad de transformaciones culturales en la condición social de varones y mujeres si no se modifican las mentalidades.

En términos generales, es posible afirmar que el psicoanálisis logró una descripción aguda de muchos procesos subjetivos, pero erró seriamente cuando trató de establecer los factores determinantes de los mismos. Freud no fue ajeno a este riesgo y no dudó en manifestar que la metapsicología era de algún modo una mitología. Esos conceptos o modelos teóricos podrían ser modificados si la experiencia los pusiera en cuestión. Y eso es, lo que efectivamente ha sucedido, no en cuanto a los grandes modelos teóricos, pero sí en lo que se refiere a las consideraciones freudianas acerca de las mujeres.

En una teoría que ha hecho de la psicosexualidad una piedra fundamental de su edificio, los yerros en el tema de la feminidad no son, como escribió Freud (1933), "un trabajo psicoanalítico de detalle", sino que ponen en entredicho algunos supuestos del marco teórico. 
Si muchas de las construcciones freudianas sobre la sexualidad femenina no han resistido la prueba del tiempo, esto se debe a que las mujeres han cambiado mucho en pocas décadas. La velocidad del cambio social ha transformado las relaciones de género y las subjetividades femeninas y masculinas hegemónicas también han experimentado algunas transformaciones notables, aunque la inercia del pasado persiste en muchos aspectos. De ese modo se hizo evidente el carácter epocal de algunas observaciones psicoanalíticas y el hecho de que no responden a invariantes anclados en la diferencia sexual anatómica, tal como se supuso en los comienzos de la teoría.

¿Cuáles son los pilares que se han revelado tan endebles en el edificio freudiano sobre la feminidad?

La referencia a la hipertrofia asignada a la envidia fálica de las mujeres en la teoría freudiana debe ser breve por el hecho de que existe hoy consenso acerca de que se trató de una percepción sesgada. Si bien las niñas manifiestan de modo literal su deseo de poseer un pene, esta envidia de origen pregenital sólo pudo transformarse en un tema considerado como crucial para el psiquismo femenino en un contexto discriminatorio para las mujeres. Hoy disponemos de material clínico que nos permite sostener que también los varones envidian dolorosamente los senos de la madre y su capacidad para albergar una nueva vida. Aceptan de modo gradual y no sin pena que su destino biológico es ser padres, no madres. He trabajado sobre este tema en los libros Género y familia (Burin y Meler, 1998) y Varones (Burin y Meler, 2000). En un contexto cultural donde el dominio masculino decrece, aparecen muchos varoncitos que expresan de forma manifiesta el deseo de tener niños al modo de la madre. Por otra parte, tal fue el caso del pequeño Hans (1909), descrito por Freud, cuya evidente preocupación por los bebés y su deseo de tenerlos en su cuerpo no fueron teorizados. De modo que la envidia fálica no es sino la manifestación en las mujeres de una tendencia envidiosa general, que también existe entre los varones. Lo que ha ocurrido es que el prestigio imaginario y simbólico asignado a la masculinidad ocultó la envidia masculina hacia la maternidad. Karen Horney (1982) ha considerado que la creación cultural masculina es una compensación por la escasa participación de los cuerpos varoniles en la gestación. La 
Psicoanálisis y género. Deconstrucción crítica de la teoría psicoanalítica...

envidia fálica femenina, observación clínica realizada al interior de una teoría interpretativa, fue, curiosamente, comprendida de modo literal, como si no existiera un significado latente para la misma. Este tratamiento teórico puede ser metaforizado como un artilugio bursátil, que intenta elevar el precio de las acciones fálicas para encubrir las carencias experimentadas por los hombres, sujetos, por causa de su condición humana, al régimen de la falta. Solo he encontrado este tema -o complejo-, hipertrofiado, en una paciente que fue, efectivamente, discriminada por su familia a los fines sucesorios, en función de su condición femenina.

Una vez comentado este aspecto de la teoría clásica, podemos ordenar la exposición realizando un análisis crítico de cuestiones teóricas tales como la atribución de pasividad a las mujeres, el masoquismo femenino, el narcisismo femenino y el Superyo de las mujeres.

\section{La pasividad}

Un vicio epistemológico indujo a Freud $(1924,1925,1931,1933,1937)$ a considerar, aunque de modo reluctante y contradictorio, que la pasividad, o al menos las metas sexuales de fin pasivo, constituyen una característica del psiquismo de las mujeres. Podemos considerar este supuesto como un extravío teórico que se sustenta en una versión demasiado literal y genitalizada de la teoría de la sexualidad humana.

Freud observó, con mayor agudeza que ninguno de sus contemporáneos, las características psíquicas de los sujetos de su entorno. Las mujeres, en un contexto social histórico en el cual su destino principal era el matrimonio y su tarea la maternidad, recién llegadas al campo del saber en el cual algunas pocas participaban como discípulas, privadas en su mayor parte del acceso a las ocupaciones remuneradas, presentaban, en efecto, tendencias psíquicas hacia la pasividad. En lugar de relacionar estas características subjetivas con los arreglos culturales vigentes, el creador de la teoría psicoanalítica los refirió a la estructura receptiva de los genitales femeninos. De este modo tomó un camino errado, al estudiar la subjetividad como un subproducto del 
cuerpo erógeno, concebido de modo insular y desarraigado del contexto social, económico, cultural y simbólico en el que se construyen los sujetos. Esta tendencia endogenista no se advertía en un trabajo temprano, escrito en 1908, "La moral sexual cultural y la nerviosidad moderna", donde estableció de modo explícito un nexo entre los arreglos culturales, y más específicamente la doble moral sexual vigente, y las características subjetivas observables en varones y en mujeres. La inhibición derivada de la excesiva represión sexual de las mujeres, no permitía el despliegue de la pulsión epistemofílica, o deseo de saber. Para Freud, el deseo de saber deriva de la curiosidad infantil por conocer el origen de los niños y comprender la diferencia entre los sexos. Las niñas, más impedidas que sus hermanos en su afán investigador, veían entonces obturado su desarrollo intelectual. Esto explicaba su bajo rendimiento académico y su escasa contribución al desarrollo cultural, afirmación con la cual se oponía a Moebius, autor de un "best seller" de la época, que había titulado La imbecilidad fisiológica de la mujer. En este aspecto, el desarrollo de los escritos freudianos fue claramente involutivo, ya que más adelante su pensamiento adquirió un claro tinte biologista, tanto que llegó a considerar que la carencia de pene era lo que explicaba la escasa contribución femenina al desarrollo cultural. Retornaré sobre este tema cuando analice los desarrollos freudianos acerca del Super Yo de las mujeres.

Si retomamos el análisis de la atribución de pasividad a las mujeres, veremos que el creador del psicoanálisis explicaba las tendencias pasivas observadas en las mismas, haciendo referencia a la anatomía genital femenina. Es por eso que, al describir lo que denominó "el cambio de objeto", o sea el pasaje del apego infantil de la niña con respecto de la madre hacia el deseo amoroso respecto del padre, caracterizó a este proceso por un ascenso de la pasividad psíquica. La meta sexual imaginaria, consistente en ser penetrada por el padre, fue definida como pasiva, y se extendió esta característica de los genitales a toda la personalidad y a las actitudes vitales de las mujeres.

He considerado (Meler, 1987, 1993, 1997 y 2005) que esta caracterización de la vagina como un órgano pasivo fue imaginaria, y esto se hace manifiesto cuando 
Psicoanálisis y género. Deconstrucción crítica de la teoría psicoanalítica...

comprobamos que, en estudios psicoanalíticos realizados algunas décadas más tarde, la imagen de los genitales femeninos había cambiado de carácter.

En diversos estudios etnográficos sobre pueblos "primitivos", los genitales femeninos aparecen como exigentes, aferrantes, tomadores y voraces (Meler, 1987). La constatación de la diversidad de mitos y prácticas culturales posibles que se elaboran en torno de este tema permite advertir el carácter imaginario de la vagina freudiana, representación construida partir de las observaciones clínicas realizadas sobre mujeres pasivizadas por un contexto cultural que les negaba la adultez social, promoviendo su pasaje de la tutela del padre a la del marido.

Jeannine Chasseguet Smirgel (1977), en un trabajo titulado "La culpabilidad femenina", elaboró una curiosa teoría que explicaba la subordinación social de las mujeres por sus sentimientos inconscientes de culpa, derivados de sus deseos receptivos referidos al pene del padre. Esos deseos, imperiosos y aferrantes, eran una fuente de culpabilidad, sobre todo en mujeres cuyos padres estaban dañados, ya sea física, psíquica o socialmente, y sus madres, por el contrario, eran figuras fuertes e íntegras. De acuerdo con la experiencia clínica de la autora, estas mujeres fantasearían que el padre fue dañado por la madre durante la unión sexual entre ambos. Esta observación, sin duda interesante, dio origen a una generalización abusiva, que explicaba la subordinación de las mujeres por sus deseos de reparar la figura dañada de su padre, ofreciéndose, a la manera de la Antígona de Edipo en Colono, como báculo para el sostén de la figura paterna claudicante. Ellas elegirían funcionar como ayudantes para la consagración narcisista de los varones amados, postergando sus propios logros, debido al temor fantaseado de haberlos perjudicado por causa de sus voraces deseos genitales receptivos. Como es fácil observar, la vagina freudiana, un genital más bien atónico y laxo, ha dado lugar a otra construcción imaginaria, la vagina smirgeliana, un órgano aferrante, exigente, demandante al límite del posible daño del genital masculino, objeto de su deseo.

Es posible ofrecer otra lectura acerca del sentimiento de culpabilidad que Chasseguet Smirgel detectó en sus pacientes, hijas de padres dañados y de madres 
íntegras. Muchas mujeres de hoy, sobre todo aquellas que han obtenido logros en el ámbito público, antes reservado para los varones, ocupando posiciones de poder y ejerciendo su autonomía, experimentan angustias de desgenerización. El temor a perder la feminidad, que como expresó Emilce Dio Bleichmar (1985), es un organizador mayor del psiquismo, puede estimular en ocasiones que las mujeres disimulen sus éxitos, tal como lo observó Joan Rivière (1966) en su artículo acerca de "La feminidad como mascarada", un clásico del psicoanálisis kleiniano. La innovación cultural puede eventualmente ser experimentada como trasgresión, y si en el curso de un análisis se detecta una necesidad inconsciente de castigo asociada con esta motivación, es tarea del/la psicoanalista acompañar a su paciente en la superación de esa culpabilidad paralizante y destructiva, en lugar de potenciar y corroborar el sentimiento de culpa, tal como hizo en su momento la psicoanalista citada.

La elaboración de una teoría general sobre la subordinación cultural de las mujeres a partir del estudio de algunos casos clínicos resulta inaceptable. Los procesos histórico-sociales no pueden ser explicados sobre la base de tendencias subjetivas que se consideran universales, y cuya sumatoria daría lugar a desenlaces grupales construidos de un modo aditivo. Esta extrapolación desde el nivel individual del análisis del psiquismo hacia la elaboración de hipótesis acerca de la cultura resulta poco sostenible. Los procesos culturales obedecen a una legalidad propia, en la cual las tendencias biopsíquicas universales, o propias de la especie, juegan sin duda un rol, pero esto ocurre en el contexto de sucesos que afectan a grandes grupos humanos y ante los que se elaboran de modo colectivo representaciones, valores y prácticas sociales.

Repasemos entonces las características del error epistemológico freudiano al atribuir a las mujeres una tenencia psíquica esencial hacia la pasividad, o caracterizar sus metas sexuales como de fin pasivo:

- Se realizan observaciones psicosociales que advierten una tendencia subjetiva hacia la pasividad entre las mujeres de comienzos del siglo XX.

- Se refiere esta tendencia observada a la anatomía de los genitales femeninos, concebida de modo imaginario como pasiva. 
Psicoanálisis y género. Deconstrucción crítica de la teoría psicoanalítica...

- Se explica la conducta y actitudes de todas las mujeres, sobre la base de esta supuesta configuración anatómica de sus genitales.

Este razonamiento circular, lleno de contorsiones penosas, es fácil de evitar si concebimos la subjetividad como una construcción social histórica (Foucault, 1980 y 1986), caracterizamos a las sociedades humanas por la dominación masculina (Bourdieu, 1991 y 1998), y comprendemos que fue el estatuto de las mujeres en la cultura lo que ha explicado su dependencia y la limitación de su creatividad, una situación que, al revertirse de modo veloz, demuestra su carácter contingente, no estructural.

\section{El masoquismo femenino}

Al estudiar la misteriosa tendencia humana que consiste en obtener placer del dolor, Freud inauguró un importante aspecto de la teoría, cuyo mayor valor consiste en alejarse de una versión funcional de la sexualidad y del psiquismo. La paradójica búsqueda del propio mal fue teorizada en "Más allá del principio del placer" (1920) y ha permitido que, más tarde, Castoriadis (1992 y 1993) caracterizara al ser humano como "un animal loco", cuya psique está desfuncionalizada, o sea, que no presenta un funcionamiento siempre coherente, acorde con los fines de la autoconservación.

Pero, nuevamente, al interior de esta fructífera indagación, la feminidad apareció como un exponente del extravío del pensamiento freudiano, demasiado solidario, en este aspecto, del sentido común sexista de su época.

En sus trabajos sobre este tema, vincula la meta sexual femenina, ya caracterizada como pasiva, con la tendencia a obtener placer en el dolor, generando así una categoría hoy inaceptable: el masoquismo femenino.

En 1919, publicó su artículo "Pegan a un niño. Contribución al conocimiento de la génesis de las perversiones sexuales". Allí se refiere a fantasías eróticas acompañantes de la masturbación, que consistían en escenas donde se castiga a un niño en público. Los casos en que se basó fueron cuatro mujeres y dos varones, estos últimos 
con una perversión masoquista instalada. La aparición de estas fantasías era temprana, alrededor del quinto o sexto año de vida. No se registraba satisfacción ante escenas reales de violencia, sino que debían ser fantaseadas y atenuadas. El niño era castigado con la cola desnuda. Freud consideró que este tipo de fantasía infantil constituye un rasgo primario de perversión, que no siempre desemboca en una parafilia en la adultez. Enfocó su análisis en los sujetos femeninos, aunque luego se refirió también a los varones. Como relacionó el goce sadomasoquista con el Complejo de Edipo, consideró que la posición erógena femenina se expresa fácilmente a través de fantasmas masoquistas, o sea, que los anhelos amorosos de las niñas pueden transmutarse en fantasías de paliza, debido a que, según pensó, las metas sexuales de las mujeres son pasivas. Este es un punto de importancia para nuestro tema, por que se entiende que buscar o permanecer en situaciones de maltrato pueda explicarse, siguiendo esta línea de pensamiento, sobre la base de su equiparación imaginaria con un acto amoroso.

Freud describió tres fases en la génesis de la fantasía de castigo, de las cuales sólo la última es consciente, mientras que las dos primeras son el resultado de una construcción. La primera constituiría la expresión del odio celoso hacia algún hermano (el padre pega al niño que yo odio), la segunda, de índole masoquista, sería un equivalente de la satisfacción sexual anhelada, obtenida mediante una unión amorosa con el padre, y por ese motivo permanecería inconsciente, y la tercera, en apariencia sádica, se solía expresar a través de una escena escolar, donde varios niños eran azotados por un representante paterno (maestro). Esta fantasía estaba acompañada de excitación sexual y masturbación. La primera fantasía expresa el deseo hostil hacia el hermano, o sea el anhelo de ser amadas en forma exclusiva, la segunda es producto de la represión y la regresión sádico-anal del deseo fálico-genital hacia el padre, siendo estos expedientes defensivos implementados debido a la interdicción del incesto, y la tercera, se considera como una expresión encubridora de la segunda. En uno de los casos de pacientes varones, el deseo masoquista aparecía en forma consciente, pero quien castigaba era la madre. Las prácticas prostibularias sadomasoquistas constituyen una evidencia de la persistencia actual de estos deseos en los varones. 
Psicoanálisis y género. Deconstrucción crítica de la teoría psicoanalítica...

Cuando aparecen estas fantasías, los niños azotados son generalmente varones, tanto si quienes fantasean son niñas o muchachos. Freud explicó esta observación sobre la base de la identificación masculina de las niñas, o "complejo de masculinidad", actitud que suele surgir como resultado de la renuncia edípica, por la cual las niñas se extrañan por completo de su papel sexual. En un trabajo posterior (1925), aventuró la hipótesis de que el muchachito castigado representaría el clítoris de la niña. Es posible que el núcleo de verdad en esta hipótesis se refiera a la erotización defensiva de la terrorífica asimetría de fuerzas entre el adulto y la niña. La fantasía femenina de ser varón constituye una condensación de deseos, temores y búsqueda de elevar la autoestima.

Como vimos, en el caso de los pacientes varones, la actitud pasiva, que Freud asimila a la feminidad, se refiere a deseos eróticos de índole pasiva, deformados regresivamente, tal como ser estimulado, acariciado y amado. La madre es el personaje castigador manifiesto, pero Freud considera que el deseo masoquista se refiere al padre. Se trataría entonces de deseos homosexuales masculinos. Considera entonces que la fantasía de paliza del varón es pasiva desde el comienzo, ya que se origina en la actitud femenina hacia el padre. En la niña, la fantasía masoquista inconsciente partiría de la postura edípica considerada como normal; en el varón, de una posición que califica como la trastornada, ya que toma al padre como objeto de amor.

Es fácil percibir que si la meta sexual normal femenina es pasiva, y la pasividad se transforma en deseo de castigo por regresión, la hipótesis consistente en que muchas mujeres soportan el castigo por encontrar en el mismo un equivalente de la satisfacción erótica parezca estremecedoramente verosímil. Los varones homosexuales buscarían inconscientemente ser victimizados, también por motivos erógenos.

Vemos así desplegada una escena de carácter extremadamente humillante, ya que al hecho de ser objeto de malos tratos se agrega el supuesto de que esa condición complace a la víctima. 
Como vimos, cuestiono la asociación imaginaria que establece el psicoanálisis entre feminidad y pasividad, sustentada en una universalización espuria de observaciones psicosociales de la época.

El recurso a la erogeneidad como clave última cegó al psicoanálisis respecto de la eficacia de las relaciones de dominación en la construcción de la subjetividad, lo que facilitó los deslizamientos sexistas que constituyen el núcleo conflictivo de la teoría psicoanalítica con respecto del pensamiento feminista.

En "El problema económico del masoquismo" (1925), Freud diferencia entre masoquismo erógeno, masoquismo femenino y masoquismo moral. El masoquismo, según Freud, se observa de tres modos: como una condición previa para la excitación sexual, como una expresión de lo que denomina como "naturaleza femenina" y como una norma de conducta en la vida.

Luego de declarar en última instancia incomprensible al masoquismo erógeno, y atribuir el masoquismo moral al sentimiento de culpa o necesidad inconsciente de castigo, Freud caracteriza al masoquismo femenino como el más fácil de comprender. Y acto seguido, expone reflexiones acerca de ese masoquismo en el varón, al que se limitará en función del material disponible, ya que, de modo sorprendente, no posee casuística de pacientes mujeres.

En los casos de masoquismo femenino, la precondición erótica consistente en ser atado, maltratado, ensuciado, denigrado, se asocia en el imaginario freudiano con lo que describe como una situación característica de la feminidad, es decir que significa ser castrado, ser poseído sexualmente o parir.

Encontramos aquí una extraña unificación de tres situaciones: la primera, ser castrado, sólo puede referirse a la feminidad si se sostiene al pie de la letra la concepción aristotélica de la mujer como un hombre menor o castrado (A.M. Fernández, 1993). En el contexto de un orden simbólico fuertemente patriarcal, es posible que muchas mujeres se experimenten como habiendo sido objeto de castración, como consecuencia de la ausencia de nominación para su diferencia sexual. Pero de ahí a considerar que la experiencia de castración es específica de lo que Freud llama la 
Psicoanálisis y género. Deconstrucción crítica de la teoría psicoanalítica...

"naturaleza femenina" existe un deslizamiento vertiginoso entre el imaginario masculino acerca de la feminidad y la experiencia femenina en sí misma.

En cuanto a la "posesión sexual”, ésta es una metáfora que expresa fantasías eróticas asociadas al hecho de ser dominada. Estas fantasías, u otras donde existe una referencia a "la entrega", son parte de una amplia gama de deseos parciales propios de la sexualidad humana, que la dominación intergenérica ha propiciado en las mujeres, reprimiéndolos severamente en los hombres. Por lo tanto, la asimilación generalizada de la posición femenina al deseo de ser poseída es ideológica, e implica una replicación de la violencia patriarcal al interior de la teoría psicoanalítica. Esta violencia consiste en la denegación de la existencia de deseos activos y aún sádicos en las mujeres, que pueden ponerse en juego de forma flexible según el momento y los avatares del vínculo. El único aspecto respecto del cual podría existir un acuerdo es en el referido al parto, ya que, sin duda, sólo las mujeres damos a luz. Pero, ¿de qué parto estamos hablando? Da la impresión que el imaginario freudiano de este artículo alude a un parto experimentado como estallido y desgarramiento. Las experiencias del parto son en la realidad extremadamente variables; así como existen mujeres que se sienten desestructuradas, otras dan a luz merced a un eficaz control obsesivo, donde el dolor y la ansiedad son mantenidos a raya, siendo lo característico de esa experiencia el autocontrol sobre el cuerpo y de la acción del otro dentro del sí mismo.

De modo que, una vez más, se ha confundido la sexualidad femenina con las fantasías masculinas respecto de la posición sexual femenina, fantasías teñidas de sadomasoquismo, que son prototípicas de los varones durante la pubertad. Freud mismo aclara que denominó a esta forma de masoquismo "femenino", aunque muchos de sus elementos apuntarían a la vida infantil.

De mayor riqueza heurística me parece el concepto de "masoquismo erógeno", sin el cual no es posible captar el aspecto pulsional de las relaciones de dominio y maltrato. Recordemos que ya en los Tres Ensayos (1905), Freud formuló la tesis de que "la excitación sexual se genera como efecto colateral a raíz de una gran serie de procesos internos, para lo cual basta que la intensidad de éstos rebase ciertos límites 
cuantitativos". La existencia de una coexcitación libidinosa provocada por una experiencia de dolor o displacer, funda, de acuerdo con Freud, la base fisiológica para que se erija la estructura psíquica del masoquismo erógeno. Al masoquismo primario, constituido por el remanente de pulsión de muerte que el sujeto no pudo proyectar como pulsión de dominio sobre el exterior, se agrega la reintroyección del sadismo proyectado.

He propuesto (Meler, 1997) sobre la base del concepto de masoquismo erógeno, el de "erogeneidad de subordinación", relacionado con el hecho de que los sujetos inmersos en situaciones penosas, potencialmente traumáticas, es decir desestructurantes para su Aparato Psíquico, recurren, como forma de ligar la cantidad de estímulo que los desborda, a la coexcitación erótica. Esta respuesta puede en ocasiones hacer tramitable una experiencia, evitando así la locura o la muerte. Dado que los sujetos subordinados, entre los cuales se encuentran las mujeres, están expuestos en alto grado a estímulos traumáticos, me parece preferible crear esta denominación, ya que el concepto de "masoquismo femenino" tiene el inconveniente de naturalizar la asociación entre feminidad y sufrimiento. "Erogeneidad de subordinación" presenta la ventaja de ser extensible a los niños varones, los ancianos u otros sujetos expuestos a abusos o torturas. Muchas de las características atribuidas al género, se explican en realidad en función de las relaciones de poder, como ya lo señalara Jean Baker Miller (1987). Este concepto resulta útil para comprender situaciones donde el sujeto reitera decisiones que resultan lesivas para su ser.

Pero queda en pie el carácter insatisfactorio de un enfoque teórico que enfatiza unilateralmente la pulsión. La concepción que subyace al enfoque pulsional es la de un ser humano aislado, narcisista, que busca al semejante como proveedor de satisfacciones eróticas, de las que disfruta sin percepción ni consideración hacia la alteridad (Chodorow, 1984). Me identifico con los psicoanalistas que resaltan la importancia del vínculo interpersonal, y la significación diversa de las experiencias de satisfacción de acuerdo con el sentido que adquieran, en términos de la respuesta de los 
Psicoanálisis y género. Deconstrucción crítica de la teoría psicoanalítica...

otros significativos, y de la estima de sí que consoliden o destruyan. La estima de sí, a su vez, depende del reconocimiento de los otros.

De modo que si no aceptamos el concepto freudiano de "masoquismo femenino", es conveniente abrevar en la producción del psicoanálisis intersubjetivo. En Estados Unidos, Jessica Benjamin (1997), en su análisis acerca del problema de la dominación erótica, se enmarca en el estudio de la intersubjetividad. Según esta autora, la dominación y la sumisión son el resultado de una ruptura de la tensión que es necesario mantener entre la autoafirmación y el mutuo reconocimiento. Esta tensión que permite que el sí-mismo y el otro establezcan un vínculo de reciprocidad, de paridad. Se sustenta en el discurso hegeliano para plantear la paradoja del reconocimiento, ya que al mismo tiempo que la respuesta que proviene del otro es lo que da significado a los sentimientos y acciones del sí mismo, existe una tendencia a desconocerlo e instrumentalizarlo, que si triunfa, nos arroja nuevamente a la soledad, por ausencia de interlocutor. Benjamin considera que el "reconocimiento mutuo" incluye sintonía emocional, influencia mutua y estados de ánimo compartidos.

Al igual que Chodorow (1984), discrepa respecto de una perspectiva predominantemente pulsional. Ella concibe al infante no sólo como un buscador de satisfacción, sino como un buscador de estímulos sociales tal como lo plantean los teóricos del apego. Contrapone a la teoría de Margaret Mahler (1972) sobre el desarrollo temprano, que enfatiza la separatividad y la individuación como meta del desarrollo evolutivo del infante, la perspectiva de Daniel Stern (1992), quien postula la existencia de un interés social inicial en el niño. Considera que la concepción intersubjetiva sostiene que el individuo crece en las relaciones con otros sujetos y a través de ellas. Plantea un modelo teórico que estudie, en lugar de la relación de un sujeto con su objeto, la relación de un sujeto con otro sujeto.

Resulta evidente la pertinencia política de tal modelo del desarrollo para las mujeres, asignadas a la posición de objetos para el sujeto hegemónico masculino.

La autora plantea que existe siempre una tensión paradójica entre el anhelo de asimilar el otro al sí mismo y la necesidad de conectarse con él como un sujeto exterior. 
El bebé trata de objetivar a su madre debido a su profunda dependencia, pero debe fracasar en este intento, y encontrarse con la existencia de una subjetividad materna exterior e irreductible a sí. Para Benjamin, el reconocimiento mutuo, la capacidad de reconocer al otro, es una meta del desarrollo tan importante como la separación.

Si la madre no acepta su fracaso en crear un mundo perfecto para el infante, y la herida narcisista que esto implica, se somete a las demandas del niño, que p. ej., en la fase de reacercamiento (Mahler, 1972.) son tiránicas. El niño, ante esta falta de límites, se encuentra solo, sin objeto.

Según piensa la autora, es necesario comprender el proceso de alienación mediante el cual el deseo de independencia y el deseo de reconocimiento se transforman en violencia y sumisión eróticas.

La dominación es un intento de negar la dependencia, anulando la subjetividad del otro. Pero la cuestión más desgarradora, la paradoja más difícil de comprender, consiste en la preferencia de una posición de sometimiento, y éste es el tema "impensable" a que me refiero. Benjamin se pregunta sobre cómo está anclada la dominación en los corazones de quienes se someten a ella y de este modo alude al problema del masoquismo en la teoría freudiana.

Discute el planteo hegeliano, con el cual coincide Freud, acerca de que la aspiración de dominio omnipotente es universal y sólo se renuncia parcialmente a ella ante las limitaciones impuestas por el poder del otro. Desde esa perspectiva, el destino del más débil parecería ser la esclavitud. Benjamin busca un relato acerca del desarrollo humano y los vínculos, que no presente como disyuntiva inevitable la que se plantea entre la dominación o la esclavitud. Postula que el otro poderoso, al cual algunas mujeres se someten, tiene el poder que ellas anhelan. Satisfacen entonces su deseo de poder mediante la identificación con su Amo. El dolor sólo implica placer cuando involucra el sometimiento a una figura idealizada. El dolor físico es preferible en ocasiones al dolor psíquico de la pérdida y el abandono. Al perder su self, obtienen acceso a otro ser, más poderoso. 
Psicoanálisis y género. Deconstrucción crítica de la teoría psicoanalítica...

Relacionando el deseo de ser omnipotente con la pulsión de muerte postulada por Freud, Benjamin considera que cuando los deseos flexibles de entrega y dominio se escinden, se disocian, y uno de los partenaires queda fijado a la posición de dominante, mientras que el otro (en general la otra) se ubica como dominado, se llega a la pérdida de tensión, o sea a un estado cercano a la muerte, al menos la muerte del deseo.

Existe una asociación entre sadismo y masculinidad, así como entre masoquismo y feminidad. Esto no implica que no haya mujeres sádicas, y desde ya, la perversión masoquista erógena es predominantemente masculina.

El proceso de diferenciación reactivo del varoncito respecto de su madre, planteado por Stoller, Chodorow y Dio Bleichmar, favorece el establecimiento de límites del self que son a la vez barreras. La empatía se dificulta y el dominio masculino se ve facilitado. La tendencia es a objetivar a la madre y luego a las mujeres. La empatía supone "ponerse en el lugar" del otro, y eso es lo que los varones buscan evitar, por temor a perder su identidad. Según considera Benjamin, la dominación erótica representa una expresión especialmente intensa de angustia masculina y una defensa ante la madre.

Las mujeres, por su parte, no tienden a negar al otro sino a negarse a sí mismas. Al no necesitar desidentificarse respecto de la madre, las mujeres no ponen énfasis en la independencia. La dificultad para el despliegue de la agencia femenina se agrava por el hecho de que la madre en la mayor parte de los casos es una persona que renunció a su propia subjetividad, y, para la niña, la identificación con el padre implica el riesgo de desfeminización. La sumisión femenina replica la actitud materna.

Benjamin afirma que la percepción que los niños tienen acerca de la carencia de subjetividad de la madre crea una propensión hacia el masoquismo femenino y el sadismo masculino. Como vemos, la madre moderna ha sido una creación colectiva problemática, tal como lo propuse anteriormente en un trabajo sobre el tema de la maternidad (Meler, 1991).

Existen entonces otros modelos alternativos al creado por Freud sobre el masoquismo femenino, donde se naturalizó la tenencia femenina hacia el sometimiento 
y la búsqueda del dolor a través del auto sacrificio. Esta tenencia subjetiva puede ser comprendida hoy como el correlato de los arreglos culturales que establecen la dominación masculina.

\section{El narcisismo femenino}

El concepto de narcisismo fue creado por Freud en 1914, y tuvo la finalidad de contestar la postura junguiana, que planteó la existencia de procesos psíquicos animados por una energía que no consideraba propiamente sexual. Jung propuso en consecuencia la ampliación del concepto de libido, con el fin de considerarla como una energía psíquica de carácter general. Freud también se opuso en este escrito a la postura adleriana, que asignaba eficacia motivadora a la voluntad de poder, línea teórica que hoy los estudios de género han retomado con vigor, aunque el concepto que utilizamos se define específicamente como "relaciones de poder".

En términos generales, el concepto de narcisismo se refiere a la investidura libidinal del sí mismo, es decir que los sujetos no solo dirigen su amor hacia los objetos del mundo, sino que en alguna medida, se aman a sí mismos. Definido en términos teóricos, el narcisismo es el complemento libidinoso de la pulsión de autoconservación.

Su existencia fue detectada por a través de los delirios psicóticos de grandeza, que revelan la omnipotencia imaginaria atribuida al Yo. La libido es sustraída a los objetos y reinvertida sobre el sí mismo; el sentimiento de engrandecimiento deriva entonces de esta súbita "riqueza" libidinal adquirida por el propio Yo.

La omnipotencia del pensamiento caracteriza también a los niños y a los pueblos primitivos, en los que los recursos mágicos para hacer frente a los avatares de la realidad evidenciarían esta modalidad regresiva de pensamiento.

El enamoramiento sería, según pensó Freud, el estado psíquico antagónico con la investidura narcisista del propio ser: toda la libido se destina hacia el objeto amado, y la autoestima desciende por ese motivo. La grandeza del Yo da lugar a la humildad y a su correlato; la idealización amorosa. 
Psicoanálisis y género. Deconstrucción crítica de la teoría psicoanalítica...

Para avanzar en la construcción del nuevo concepto, Freud estudió los procesos psíquicos que acompañan a la enfermedad orgánica, a la hipocondría y a la vida amorosa. El enfermo se retrae del amor hacia los demás y concentra toda su energía sobre sí mismo. Es el modo de hacer frente a su sufrimiento, y de algún modo, este egoísmo es necesario. En el caso de la hipocondría, las sensaciones corporales penosas no tienen sustento en alteraciones orgánicas. Freud considera que se deben a una investidura libidinal realizada sobre el órgano que molesta, y que es análoga a la excitación genital. Si la erogeneidad es una propiedad de todos los órganos, esto explica que uno de ellos pueda ser objeto de una investidura tal que genere sensaciones dolorosas.

Vemos entonces que el narcisismo, o investidura libidinal del sí mismo, se asocia con la psicosis, el estado infantil, la mentalidad primitiva, la enfermedad orgánica, y la hipocondría. Si bien el creador del psicoanálisis considera que un cierto grado de amor al sí mismo es necesario, está claro que ubica la salud mental del lado de la capacidad de amar al semejante.

Sobre esta base se interna en el estudio de la vida amorosa entre mujeres y varones. Establece que el prototipo del objeto de amor es la imagen de la madre, la persona que ha satisfecho las necesidades elementales durante el desamparo infantil. Pero encuentra que algunas personas eligen su objeto amoroso sobre la base del amor a sí mismos; ésta es, piensa, la situación de los homosexuales.

Quedan así delineados dos modelos, dos caminos para la elección de objeto de amor: la elección por aposición, o sea, hecha sobre la base del modelo del objeto satisfactor de las necesidades y la elección narcisista, realizada sobre el modelo del Yo.

Es posible discutir estos supuestos, y así lo hice en el libro Varones (Burin y Meler, 2000). Respecto de la consideración freudiana de las elecciones homosexuales de objeto como narcisistas y de su idealización de la posición subjetiva de los varones enamorados, podemos recordar que existen elecciones heterosexuales donde el objeto de amor representa al sujeto en un estado anterior o en un estado ideal. Es más frecuente que sean los hombres quienes eligen a las mujeres sobre la base del niño amado que 
ellos fueron. Las hacen objeto de todas las atenciones que añoran, al tiempo que las controlan y dominan, aunque sea de modo benévolo. Entre las mujeres es fácil encontrar un tipo de elección amorosa donde el hombre amado representa lo que ella hubiera deseado lograr por sí misma y no se atrevió a intentar. La esposa del médico o del ingeniero, y en términos generales, todas las mujeres que obtienen su estatuto social a través de los logros de su marido, se encuentran en esta situación. De modo que la elección heterosexual de objeto, y es más, las más usuales y convencionales entre las mismas, revelan sus aspectos narcisistas.

Entre las parejas homosexuales, a las que se ha atribuido "a priori" un carácter narcisista por tomarse como objeto a alguien del mismo sexo, que se supone representaría una imagen especular del propio ser, hay algunas donde existe una diferencia de estilos subjetivos, y donde el amor no se reduce a un eco del sí mismo sino que se logra el desarrollo de empatía hacia el otro diferente.

Así es como desordenamos la taxonomía amorosa freudiana, y queda de manifiesto su carácter sesgado en función de prejuicios misóginos y homofóbicos.

En términos generales, la elección como objeto de amor de alguien que nos recuerda a quien nos auxilió en la necesidad se caracteriza también por el egoísmo. Por lo tanto, la elección pretendidamente objetal revela que el motor que la anima es, nuevamente, el amor a sí mismo.

Pero lo que importa destacar es que Freud considera que el pleno amor de objeto realizado sobre la base del apuntalamiento en el modelo satisfactor de las necesidades es característico del varón. Los varones sobreestiman a su objeto sexual e idealizan a la mujer amada.

¿Qué ocurre con las mujeres? Describe un acrecentamiento de su narcisismo en el período puberal, que relaciona con la conformación de los órganos sexuales femeninos. Por lo tanto, no constituyen un objeto de amor en toda la regla. Si son hermosas, desarrollan una complacencia consigo mismas, que según dice Freud, las resarce de lo que denomina como la atrofia que la sociedad les impone en materia de elección de objeto. Por lo tanto, ellas no aman sino a sí mismas y se complacen en ser 
Psicoanálisis y género. Deconstrucción crítica de la teoría psicoanalítica...

amadas. Estos seres atractivos son comparados con los niños, cuyo egoísmo atrae, los felinos, autosuficientes y, utilizando metáforas nietszcheanas, con los humoristas y los criminales, que han retenido la posición subjetiva que engrandece a su Yo.

¿Cómo se explica Freud el amor maternal, luego de haber pintado este cuadro donde las mujeres son percibidas como seres autosuficientes e incapaces de amar? Es fácil: el hijo ha sido una parte del cuerpo propio, y el amor hacia el mismo no es más que una extensión del propio egoísmo, un truco de la Naturaleza para lograr mediante este expediente, los cuidados necesarios para la continuidad de la especie. Para coadyuvar en este proceso, algunas mujeres perciben en sus hijos varones el niño que ellas creyeron ser antes de reconocer la realidad de la diferencia entre los sexos, realidad por cierto penosa dada su "atrofia fálica". A través del amor que les prodigan, se aman, una vez más, a sí mismas.

Considero que encontramos en todo sentimiento amoroso una dosis de amor al otro y otra de amor al propio ser, y que estos componentes del mismo no se reparten de modo diferencial a través de la línea marcada por la diferencia entre los sexos. Para dar un ejemplo, los obsequios y halagos de que algunos varones hacen objeto a sus mujeres amadas están muchas veces destinados a la contemplación de los otros hombres, y constituyen un alarde de virilidad y de poder económico, o sea que tienen una finalidad narcisista: tal es el caso prototípico de las joyas, que la mujer exhibe como muestra del amor de que es objeto, pero que, a la vez, dan testimonio del rango social del varón donante. Si los varones fueran tan capaces de amor de objeto, los terapeutas de pareja no atenderíamos con tal frecuencia las consultas por causa de una crisis conyugal surgida al conocerse una prolongada infidelidad masculina, o infidelidades habituales, practicadas de modo "deportivo", o sea sin compromiso emocional.

En el caso de las mujeres, considero que Freud ha confundido la inhibición erótica producto de la doble moral sexual que él mismo teorizó en 1908, con la autosuficiencia y la indiferencia amorosa. Las mujeres de su tiempo, estaban educadas para disimular con cuidado cualquier manifestación de deseo. Aún hoy, exponerse a demostrar un deseo amoroso que puede no ser correspondido, es una situación que la 
mayor parte de las mujeres considera humillante. Prefieren entonces disimular, y esperan de modo aparentemente pasivo las señales de interés por parte del hombre. Este es un "guión erótico" que pauta los rituales de cortejo en diversas culturas, aunque no en todas. No es una evidencia de la indiferencia de las mujeres, sino la pasivización de su sexualidad.

El reparto freudiano, que ubica a las mujeres del lado de la psicosis, la perversión, la enfermedad y la hipocondría y asigna a los varones el amor hacia los demás, el altruismo, la donación, la salud mental y la cultura, no es más que una expresión de un simbolismo social producto de la dominación masculina, del cual la teoría psicoanalítica ha quedado prisionera por la dificultad para hacer consciente ese inconsciente cultural.

\section{El superyo}

Freud (1905) ha planteado un vínculo estrecho entre el sentido ético y la capacidad sublimatoria que desarrollan tanto los sujetos como los colectivos sociales. Debido a su concepción energética del Aparato Psíquico, consideró que cuando se plantea una renuncia a la satisfacción pulsional directa, el monto de energía así retenido puede encauzarse a través del trabajo sublimatorio. Se produciría entonces una modificación de la meta pulsional originaria transformada a través de ese expediente defensivo en una meta socialmente valorizada.

Pese a que muchas lecturas posteriores han querido decodificar en diversas claves el discurso freudiano, considero que el creador del psicoanálisis expresó a este respecto su convicción acerca de que la diferencia sexual anatómica determinaba una constitución diferencial de la formación Super Yo para varones y mujeres (Freud, 1925). La diferencia se traducía en términos de desarrollo pleno versus déficit, y dependía de la modalidad específica de elaboración de la problemática edípica: sepultamiento para los varones, amedrentados por la amenaza de castración y disolución paulatina para las mujeres, desalentadas de antemano ante la percepción de una 
Psicoanálisis y género. Deconstrucción crítica de la teoría psicoanalítica...

castración ya realizada (Freud, 1923). Solo un Edipo sepultado, un Edipo alojado en "el fundamento" podía dar lugar a un Super Yo abstracto e impersonal, que fuera capaz de reconocer la vigencia de una legalidad universal. El sentido ético de las mujeres, más particularista, buscaría transgredir las normas haciendo excepciones de acuerdo con el caso. Esta moral relativa sería, pensaba Freud, la explicación final acerca de la escasa contribución de las mujeres a la historia de la cultura (Freud, 1933).

De este modo, el padre del psicoanálisis, inmerso en un horizonte gnoseológico y epistemológico donde el reduccionismo biologista se constituyó en la caución ideológica del pensamiento discriminatorio racista, planteó su formidable convalidación del sexismo de la época y abrió sin advertirlo un debate que atravesaría el campo del psicoanálisis durante las próximas décadas.

¿Podemos plantear hoy que existen diferencias por género en la formación Super Yo y por lo tanto en el sentido ético de mujeres y varones? Para responder a esta primera pregunta debemos diferenciar entre la feminidad y la masculinidad por un lado y los varones y mujeres por el otro. Por feminidad y masculinidad entendemos las representaciones colectivas estereotipadas acerca de lo que debe ser una mujer y un varón. Estas representaciones atraviesan hoy día por un proceso de cuestionamiento y redefinición, pero no han perdido su carácter polarizado, sobre todo cuando se expresan en la conducta de padres y educadores a la hora de construir el género en los niños. Estas pautas implícitas van moldeando de forma inadvertida los destinos de pulsión, los ideales propuestos para el yo y las aptitudes y habilidades que se desarrollarán de modo diferencial. Los vínculos también se van plasmando en esa matriz, que no por muda es menos eficaz.

Sin embargo, como ya lo percibió Winnicott (1985) cuando se refirió a los “elementos masculinos y femeninos puros o destilados", nadie encarna el estereotipo, sino que los sujetos construyen su subjetividad sexuada mediante fórmulas personales no homogéneas, que se acomodan de formas diversas a las representaciones compartidas acerca de la masculinidad y la feminidad. La construcción subjetiva del género se asemeja a un mosaico, donde coexisten fragmentos identificatorios disímiles 
que van estructurando el Aparato Psíquico en sus diversas instancias (Meler, 1987). Al referirme a la identificación como el recurso mediante el cual se construye el género, estoy ubicando este proceso evolutivo en el contexto de la intersubjetividad. El género se arma en una matriz relacional, y esto se refiere tanto al vínculo con los modelos para el ser, que van pautando la conducta esperada, como a la relación con los semejantesdiferentes en cuanto al género, que sirven de contrafigura o modelo negativo.

Hecha esta diferenciación entre sujeto y estereotipo, sin embargo es fácil advertir que, pese a la tendencia postmoderna hacia la disminución de la polaridad entre los géneros, existen diferencias notables entre mujeres y hombres en lo que se refiere al sentido ético.

Son conocidos los estudios de Lawrence Kohlberg acerca del tema (Ver Gilligan, 1985). Este psicólogo de formación psicoanalítica elaboró escalas para evaluar los diversos estadios evolutivos que describió para dar cuenta de la construcción de la conciencia moral, y sus estudios confirmaron la caracterización freudiana acerca del Super Yo de las mujeres. Dicho en otros términos, el puntaje que niñas y jóvenes obtenían en los test elaborados, no alcanzaba el nivel promedio de sus contemporáneos masculinos. Carol Gilligan (1985), una discípula de ese autor, influida por el pensamiento feminista, realizó estudios sistemáticos con las mismas escalas y sus conclusiones apuntaron al hecho de que los criterios de clasificación habían sido realizados de acuerdo con el modelo masculino. Este sesgo, que se denomina androcentrismo, explicaba la baja evaluación de las mujeres. Sobre la base de otros criterios, la investigadora consideró que si bien existía una tendencia diferencial entre mujeres y varones, esta no debía considerarse como expresión de un déficit femenino. Mientras que los varones se caracterizaban por una ética abstracta definida por la defensa de los derechos individuales en conflicto, las mujeres expresaban una perspectiva que ella denominó "ética del cuidado", donde los dilemas no se planteaban en términos de derechos en litigio sino de responsabilidad hacia los más débiles. Se tendió a explicar estas diferencias en función de la división social entre el ámbito público para los varones y el ámbito privado para las mujeres, que en la década del '70 
Psicoanálisis y género. Deconstrucción crítica de la teoría psicoanalítica...

aún estaba claramente vigente. La ética del cuidado era apropiada para el ámbito de las relaciones familiares, donde los niños, jóvenes y ancianos requerían asistencia, mientras que la ética de los derechos daba cuenta de las necesidades del mundo del trabajo, donde se suponía que existían transacciones entre sujetos iguales ante la ley.

Gilligan consideró que esta modalidad de sentido ético no solo no era inferior al estilo masculino sino que reflejaba una visión de las relaciones interpersonales de eticidad más elevada, en tanto se sobreponía a la competencia para dar lugar al altruismo. Considero que si se transcriben ambos criterios éticos al ámbito de las políticas públicas, mientras la ética de derechos rige las transacciones sociales generales, la ética del cuidado se aplica al campo de las políticas sociales o de las medidas de discriminación positiva.

Este planteo resulta de gran actualidad, dada la necesidad perentoria de paliar los efectos de la exclusión mediante políticas sociales que redistribuyen los bienes económicos y simbólicos. Con esta referencia se abre entonces el debate acerca de si podemos continuar considerando a la supuesta ley universal como una expresión abstracta del respeto por los derechos, o si ha llegado el momento de develar sus aspectos desmentidos y que retornan como siniestros.

¿Una ley universal?

Como expuse en ocasiones anteriores, (Meler, 2000) la supuesta igualdad de los sujetos ante la ley encubre el establecimiento de una jerarquía al interior del género masculino. La legalidad pretendidamente universal sirve al fin de arbitrar las luchas por el puro prestigio entre varones, o sea las confrontaciones narcisistas donde el semejante es percibido como rival y su destino deseado es la aniquilación o en otros casos, la servidumbre. El desenlace de estos enfrentamientos es la institución de relaciones de dominio-subordinación.

La moral masculina es al menos doble, y mientras que las regulaciones más estrictas se aplican a los subordinados, entre los que las mujeres revistan en un estatuto específico, los dominantes se rigen por regulaciones más permisivas. 
En la historia de Occidente, a partir de la concentración del poder en manos del soberano, se produjo el advenimiento de una mentalidad que postuló la existencia de una moral universal, pero este ideal nunca logró ser operacionalizado y por lo tanto, quedó en un nivel declarativo. Es por eso que la doble moral transcurre en un estatuto ambiguo, de semiclandestinidad, y no se despliega a la luz del día, como ocurrió en el Mundo Antiguo y en el Medioevo.

Vemos entonces que los sujetos no son iguales y la ley no es universal: nuestro rey está desnudo.

\section{El Super Yo femenino}

Si el Super Yo masculino se caracteriza por la duplicidad de su normativa y la trasgresión instituida, si recurre a normas supuestamente generales para arbitrar los enfrentamientos destructivos, ¿cómo podemos caracterizar al Super Yo de las mujeres, o mejor dicho, a las prescripciones acerca del Super Yo femenino?

Los ideales propuestos para el yo de las mujeres suelen ser más modestos, al menos en aquellos ámbitos referidos a logros individuales basados en el desempeño eficaz. Siglos de reclusión en el privado favorecen que las recién llegadas al ámbito del trabajo, los negocios y la política se contenten con metas más moderadas, lo que ha inducido a Gilles Lipovetsky (1999) al error de atribuir a las mujeres un desdén intrínseco por el ejercicio del poder. Si existe un ideal absorbente y tiránico, ese es todavía el ideal maternal, basado en el imperativo altruista de la anulación del sí mismo en aras de la construcción de la subjetividad del hijo.

Por el contrario, la severidad de la conciencia moral femenina es mucho mayor que lo observado con frecuencia entre los hombres. Las estadísticas de delitos tanto contra la propiedad como contra la integridad física y la vida muestran una abrumadora mayoría masculina. Las niñas se comportan mejor en lo que hace a la inhibición de la sexualidad y de la hostilidad. Nora Levinton (2000) considera que la persistencia del apego temprano de las niñas con respecto de las madres fomenta la fusión y la vulnerabilidad ante la amenaza de la pérdida del amor. Creo necesario agregar que la amenaza de castración aflige a un sujeto que conserva la ilusión de ser fálico mientras 
Psicoanálisis y género. Deconstrucción crítica de la teoría psicoanalítica...

que la angustia ante la pérdida del amor afecta más profundamente a quienes se perciben como dependientes de su objeto amoroso. Esta diferencia no puede referirse a la diferencia sexual anatómica sino a los múltiples mensajes mediante los que se transmite a los varoncitos la esperanza de que lleguen a ser poderosos mientras que las niñas son, como dijo Helène Deustch, (1947) “sobornadas" a través de la ternura. De modo que no debemos buscar en la institución de la crianza materna la clave exclusiva para comprender la dependencia respecto de ser amadas, sino que es el destino cultural de las mujeres lo que plasma su subjetividad a lo largo de los diversos estadios del desarrollo infantil y juvenil.

\section{La creatividad}

Si no nos limitamos al análisis de los aspectos prohibitivos del Super Yo, interesa de modo especial el nexo que el psicoanálisis establece entre ética y creatividad, es decir la discusión acerca del proceso de sublimación, respecto del cual, al decir de Castoriadis (1992), el psicoanálisis ha pecado de pobreza conceptual. Como dije, la "máquina" freudiana para producir creación cultural es un expediente energético: renuncia pulsional bajo amenaza de castración y modificación de la meta de la pulsión que se destina a fines más elevados. Considero que ese régimen de procesamiento subjetivo se asemeja a los trabajos forzados, y que si bien puede dar frutos, éstos entrarán dentro del rubro de las repeticiones de los modelos convalidados. La innovación implica la posibilidad de transgredir; la creación no suele ser obra de los hijos obedientes.

En cuanto a los aportes de otros autores, vemos que, mientras Ernest Jones relaciona la sublimación con una retracción narcisista, y por lo tanto sugiere que expresa el amor al Yo, Melanie Klein refiere el trabajo sublimatorio a la relación de objeto (Ver Winnicott, 1985). Considera que creamos para reparar el daño supuesto en el objeto de amor a consecuencia de nuestro odio. Aquí ya se insinúa la génesis de una postura que presta atención a la intersubjetividad. Pienso que la dimensión narcisista de la sublimación coexiste con sus aspectos referidos a las imagos de objetos y a los vínculos interpersonales y esto es así en tanto el narcisismo nunca está disociado del amor 
objetal. Por un lado, el Yo se erige en "héroe cultural", el sujeto que crea se ilusiona con su autoimagen engrandecida, pero esto no supone que se detenga allí; los otros que aplauden en la escena imaginaria son también objetos de amor que consagran con su favor la posibilidad de amarse a sí mismo. De modo que el amor al sí mismo y el amor al otro no se contraponen sino que convergen en el acto creativo.

Otra línea teórica que aborda esta cuestión, el pensamiento de Donald Winnicott, (1985) abre interesantes perspectivas para comprender la creatividad. La experiencia vital creativa se relaciona con la capacidad de jugar y solo se instala como logro subjetivo cuando se ha constituido una individualidad con capacidad de autoexpresión ${ }^{1}$. Sin embargo, sus fuentes derivan de la fusión con una madre que posee "un pecho que es", del cual deriva el sentimiento de autenticidad y de estar vivo. Se plantea aquí una paradoja, situación tan cara al pensamiento winnicottiano, que no debe ser resuelta: la fusión inicial hace posible la constitución ulterior de una individualidad y la superación de las actitudes de acatamiento. Pero si tenemos en cuenta que esa fusión se produce con una mujer cuya creatividad se ve limitada por las prescripciones para su género, nos encontramos ante una escena de canibalismo: el individuo autónomo, el líder cultural, emerge del vínculo con la "madre suficientemente buena" capaz de crear un "ambiente facilitador". Ella es buena para el otro, pero carente de una subjetividad soberana; puede habilitar a su hijo para que pase del establecimiento de un objeto subjetivo a la constitución del sí mismo como un sujeto objetivo, pero no está invitada al festín de la subjetividad individualizada.

Estas teorizaciones son emergentes de un período histórico en el cual las representaciones prevalecientes acerca de las mujeres les atribuían la capacidad de ser deseables, "excitantes" como diría Winnicott, pero no deseantes. También podían sublimar a través de la maternidad, "construir sujetos" como destaca David Maldavsky

\footnotetext{
1 "Hacía falta una ciencia organizada antes de que los hombres y las mujeres pudiesen convertirse en unidades integradas en términos de tiempo y espacio, vivir en forma creadora y existir como individuos. El tema del monoteísmo corresponde a la aparición de esta etapa en el funcionamiento mental humano", D.W. Winnicott; "La creatividad y sus orígenes" en Realidad y Juego, Buenos Aires, Gedisa, 1985.
} 
Psicoanálisis y género. Deconstrucción crítica de la teoría psicoanalítica...

cuando se refiere a la feminidad normal (1980). Pero fue necesario atravesar por un proceso socio histórico por el cual algunas mujeres hemos podido construirnos como "individuas" para poder preguntarnos qué hacer con el acervo cultural ancestral de la subcultura femenina subordinada. Cuando simplemente se lo ha desechado, nos encontramos con modalidades de experiencia social y subjetiva deshumanizadas en el sentido de extremar los aspectos vinculados con el logro, la acumulación y la rivalidad, propios de la cultura masculina dominante. Si ya no es aceptable el recurso, en última instancia de mala fe, de construir una esfera privada donde la madre amorosa es solidaria con los propios mientras el padre guerrero depreda a los ajenos, habrá que realizar transcripciones de los códigos privados a la esfera pública y crear una ética alternativa. En el mundo globalizado, el desafío de lograr una ética genuinamente universal es enorme. En efecto, siempre hemos puesto límites dentro de los que albergamos a quienes consideramos parte integrante de los "nuestros", y fuera de los cuales quedaron los sujetos aptos para ser explotados, esclavizados o excluidos. Esta reflexión tiene una actualidad dramática dado el rebrote del racismo en los países desarrollados.

\section{Construcción de una ética interactiva}

¿Cómo podemos superar la antinomia entre una moral doméstica que expresa una bondad de cortas miras y una ética confrontativa que arbitra los conflictos propios de la rivalidad narcisista? Amar y proteger a los propios no es más que una módica ampliación del narcisismo, pero hasta el momento, los propósitos de amar al ajeno han quedado en el nivel declarativo.

\footnotetext{
${ }^{2}$ El concepto de individuo, utilizado por Winnicott, se asemeja según pienso al de sujeto autónomo, creado por C. Castoriadis. Para este último autor, el sujeto autónomo es una posibilidad que emerge a través del desarrollo histórico y no está siempre presente. Se caracteriza por la capacidad de reflexividad (tomar como objeto los propios procesos de pensamiento) y acción deliberada (término que asimila a voluntad). La acción deliberada es un término antinómico con otra categoría winnicottiana: el acatamiento. Parece perfilarse con claridad que ambos autores coinciden en vincular la creatividad y la sublimación con la autonomía. Este estatuto social y subjetivo ha sido inalcanzable para las mujeres, que solo parcial y recientemente lo hemos logrado. La subjetividad dominante encontró siempre su límite en el territorio de aquellos privados de su subjetividad debido a la subordinación.
} 
Propongo entonces establecer las bases para una ética interactiva, sustentada en la comprensión cabal de la intersubjetividad (Benjamin, 1997). La culminación de la construcción del género a lo largo del desarrollo evolutivo no consiste en el establecimiento de una escisión edípica entre el ser y el tener, sino en la capacidad de evitar la confusión y a la vez transgredir lúdicamente las fronteras de los estereotipos genéricos. Esta modalidad subjetiva es, según pienso, solo posible en la post modernidad. Los sujetos modernos han sido estereotipadamente masculinos y femeninas, los postmodernos juegan a la androginia siempre y cuando conserven con claridad un núcleo de identidad de género establecido tempranamente. Estas nuevas subjetividades podrían tal vez, aportar a la construcción de una transformación cultural que integre la legalidad universal con el cuidado hacia quienes lo requieren, con el fin de habilitar un crecimiento que es necesario para todos. No se trata de altruismo, sino de la comprensión acerca de la interrelación existente entre los sujetos, los grupos y las naciones.

\section{Nuevos rumbos}

Una vez planteadas las críticas hacia los aspectos sexistas de la teoría freudiana, resta ver cuales son los caminos alternativos para utilizar y/o elaborar nuevos modelos teóricos psicoanalíticos, que resulten adecuados para la articulación con los estudios sociales, ya que esta constituye una característica distintiva del campo interdisciplinario de los estudios de género.

En primer término es pertinente aclarar que las categorías de análisis que los estudios clásicos han utilizado para hacer inteligibles las observaciones clínicas, se han restringido a dos grandes factores determinantes: el cuerpo erógeno y los vínculos primarios. Las referencias al macrocontexto están casi siempre ausentes, con la honrosa excepción de los escritos de Karen Horney (1982).

Respecto del cuerpo y su estatuto teórico, enfrentamos una problemática compleja cuya elucidación resulta de importancia crucial (Meler, 2005). Muchos 
Psicoanálisis y género. Deconstrucción crítica de la teoría psicoanalítica...

estudios iniciales realizados dentro del campo del psicoanálisis han quedado presos de un enfoque reduccionista, y tendieron a explicar los observables en términos de una erogeneidad concebida de modo universal, como una tendencia que emana de forma endógena desde el cuerpo hacia los otros. La sistematización de las etapas del desarrollo libidinal, realizada por Karl Abraham (Ver Roudinesco y Plon, 1998), cuya simplicidad seductora ha servido como criterio ordenador para muchos desarrollos, se sustenta en el desarrollo madurativo neurobiológico que se produce durante la infancia. Esta es por cierto una verdad parcial, pero si se utiliza de modo totalizador no permite captar la complejidad de los avatares vinculares. Existen otras líneas de maduración que se refieren a la progresiva aptitud o capacidad vincular que los sujetos adquieren, la posibilidad lograda o frustra de experimentar empatía con el otro y aceptarlo como un centro de subjetividad semejante a sí mismo (Benjamin, 1997).

El desarrollo del Yo de funciones constituye otra de las líneas del desarrollo evolutivo, más estudiada por los enfoques cognitivos.

El desarrollo del sí mismo ha sido estudiado en Estados Unidos por Heinz Kohut (1971 y 1977) y aporta de modo constructivo a esta visión psicoanalítica que busca rescatarse del reduccionismo biologista. La línea teórica creada por este autor ha tenido el mérito de destacar la importancia del narcisismo para la comprensión de los procesos psíquicos, en un contexto donde se había sobredimensionado la importancia de la pulsión, entendida como una fuerza que deriva de la erogeneidad corporal.

En España, el enfoque modular transformacional creado por Hugo Bleichmar (1997), se ha elaborado con el propósito de dar cuenta de la complejidad de los procesos psíquicos, contraponiéndose a un modelo simplista que establecería una supuesta homogeneidad. El autor entiende que el psiquismo es el resultado del interjuego entre componentes, cada uno independiente de los otros en su origen y desarrollo, aunque se articulan entre sí.

La hetero-auto conservación, es una motivación cuya finalidad es preservar la vida del sujeto. Sin embargo, no surge como expresión biológicamente preformada, sino que requiere de la acción del semejante que asiste al infante, o sea de la madre, para su 
desarrollo. Como considera Bleichmar, la autoconservación es establecida en el vínculo primario, o sea que el infante es inicialmente heteroconservado y solo aprende gradualmente a cuidar de su propia existencia. De este modo surge un modelo alternativo que entiende la pulsión como un desarrollo vincular, superando el endogenismo inicial de la teoría. Bleichmar agrega que esta poderosa motivación puede ser postergada en función de conservar la vida del semejante. Acuerdo con esta observación, ya que tanto el altruismo maternal como los actos heroicos, dan testimonio de esta posibilidad.

El apego hacia un objeto privilegiado constituye otra poderosa motivación, también establecida en una trama vincular. Se observa en la relación temprana del infante con la madre, el padre y los otros cuidadores. También aparecen formas de apego en las relaciones conyugales. En algunos casos este apego cementa la relación y permite su persistencia más allá de los avatares del deseo. En otros, surgen situaciones de penosa dependencia, cuando el sujeto ha alienado su agencia, depositándola en el otro, sin el cual cree que su existencia se encuentra amenazada.

Acerca de la importancia de la sexualidad no es necesario abundar, ya que constituye una de las piedras fundamentales del edificio teórico del psicoanálisis. Sí importa para mis propósitos, destacar el modo en que el deseo surge en el encuentro del sujeto $-\mathrm{y}$ de su cuerpo erógeno- con el otro, que puede o no suscitarlo. Este surgimiento deseante siempre se engarza de modo complejo con las motivaciones que derivan de lo permitido y lo prohibido, lo valioso o lo desvalorizado, en fin, con cuestiones vinculadas con las representaciones colectivas que constituyen el orden simbólico vigente y con las producciones imaginarias y su versión idiosincrásica para cada sujeto.

El narcisismo, en tanto amor al sí mismo, a la imagen de sí, se relaciona en este enfoque de modo fuerte con la estima de sí.

El modelo de Hugo Bleichmar, al sistematizar el registro de las motivaciones de los sujetos, resulta de suma utilidad en los estudios de casos. Sin necesidad de embarcarnos en disquisiciones teóricas acerca de la autonomía o la interrelación 
Psicoanálisis y género. Deconstrucción crítica de la teoría psicoanalítica...

existente entre la sexualidad, la autoconservación, el apego y el narcisismo, estas son sin duda motivaciones de las conductas y actitudes de los sujetos, cuya discriminación a los fines del análisis resulta muy esclarecedora.

En Francia, la línea teórica desarrollada por Jean Laplanche (1993), es otro afluente de esta tendencia teórica que jerarquiza la intersubjetividad para redefinir la importancia que se ha asignado clásicamente a la pulsión. Laplanche considera que el abandono por parte de Freud de la teoría de la seducción, implicó el retorno a una concepción endógena de la sexualidad, que la refirió a un instinto anclado en la filogénesis, extravío contra el cual el creador del psicoanálisis luchó infructuosamente. Para Laplanche, el funcionamiento de la psicosexualidad humana se explica mejor mediante una referencia a la etología humana, o sea al vínculo con el otro, que, por otra parte, también ha demostrado su eficacia en los estudios sobre el comportamiento animal. La sexualidad se implanta, según piensa Laplanche, en el niño en el contexto del vínculo con el adulto, el cual emite mensajes de índole sexual de los que no es consciente, cuya índole es sobre todo, somática. Esta es su teoría de la seducción generalizada, que no implica el supuesto universal del abuso sexual contra los niños, sino que da un espacio para la consideración de sexualidad del adulto cuidador. Laplanche alerta de modo específico contra lo que define como una instintualización de la sexualidad, dicho esto en el sentido de considerar a la sexualidad humana sobre el modelo del instinto preformado, fijo y heredado.

Señala Laplanche que mientras que el Freud de Tres Ensayos (1905) destaca la desfuncionalización de la sexualidad, que se advierte tanto en el estudio de las aberraciones sexuales como en el de la sexualidad infantil, aparece de modo progresivo en su obra el intento de describir un proceso de organización integrativa. Los estadios del desarrollo libidinal señalizan este camino hacia una supuesta integración que se produciría en la adultez. De este modo se produce un viraje, que el autor califica como extravío, donde se busca construir un modelo que torne funcional a la sexualidad. Esta senda teórica conduce a pensar en un desarrollo universal, igual para todos, con lo que 
la diversidad humana se considera patológica. Los estudios de género son particularmente sensibles a todo enfoque normalizador.

El diálogo entre todos estos desarrollos psicoanalíticos está lejos de ser armonioso. Para dar un ejemplo, Laplanche se opone a las teorías anglosajonas de las relaciones de objeto, porque considera que tienden a disminuir la importancia de la sexualidad, acotándola a lo genital. Hugo Bleichmar destaca el carácter homogeneizante del enfoque de Kohut, para proponer como alternativa su modelo motivacional múltiple, inspirado en el pensamiento complejo.

Sin embargo, desde diversas perspectivas, todas estas líneas teóricas apuntan hacia un psicoanálisis constructivista, y por ese motivo es necesario elaborar un cuerpo teórico que las integre para poder establecer el paso siguiente, que consiste en articular los estudios psicoanalíticos con los estudios sociales.

Entre ellos, la importancia asignada por Michel Foucault $(1980 ; 1986)$ a las relaciones de poder, plantea un interesante desafío para quienes acostumbramos a trabajar al interior de una teoría del deseo. Foucault se define como un historiador de las ideas, y con ese enfoque construye una genealogía de la sexualidad como representación colectiva a la cual se le asigna eficacia explicativa de las conductas humanas. Esta perspectiva, si bien presenta el riesgo de caída en un relativismo histórico absoluto, permite moderar la tendencia psicoanalítica hacia la sobre generalización de observaciones propias de una época y un lugar. Mi perspectiva intenta vincular las relaciones de poder, utilizadas como categoría analítica principal de los estudios de género, con la sexualidad humana, en tanto entiendo que las inscripciones subjetivas de los arreglos colectivos se imprimen en el cuerpo erógeno.

Las representaciones colectivas han sido teorizadas por Serge Moscovici (1985), y este concepto constituye una referencia obligada cuando se estudia la feminidad y la masculinidad, que, en última instancia pueden ser conceptualizadas como tales. Este autor considera a la representación social como una modalidad particular del conocimiento, destinada a elaborar los comportamientos y la comunicación entre los individuos. Constituye un corpus organizado de conocimientos 
Psicoanálisis y género. Deconstrucción crítica de la teoría psicoanalítica...

y una de las actividades psíquicas mediante las cuales las personas dan sentido a la realidad física y social.

Un concepto alternativo es el de imaginario social, creado por Cornelius Castoriadis (1993). Su mayor mérito consiste, para los fines que propongo, en su carácter no sistemático y su apertura al cambio histórico.

Pierre Bourdieu (1991), con su concepto de práctica social, aporta una perspectiva epistemológica interesante, al alejarse del enfoque que transforma los modelos teóricos en causas eficientes de los procesos observados. Pero es su concepto de hábitus, el que resulta de mayor utilidad para construir un abordaje no biologista acerca del cuerpo. El hábitus representa las prescripciones colectivas hechas carne, es la historia cultural hecha cuerpo. De este modo, el cuerpo, una referencia psicoanalítica obligada, deja de ser considerado sobre el modelo médico para transformarse en un constructo que, literalmente, encarna la historia, una historia que es percibida como las sucesivas cristalizaciones de las tensiones entre sectores sociales por los recursos y por los bienes simbólicos.

Como puede verse, una vez realizado un análisis crítico de los sesgos epistemológicos del corpus teórico del psicoanálisis, resta un largo camino por recorrer, lo que espero resulte estimulante y alentador. 


\section{BibLiografía}

Baker Miller, Jean (1992): Hacia una nueva psicología de la mujer, Barcelona, Paidós. Benjamin, Jessica (1996): Los lazos de amor, Buenos Aires, Paidós.

-(1997) Sujetos iguales, objetos de amor, Buenos Aires, Paidós.

Bleichmar, Hugo (1997): Avances en psicoterapia psicoanalítica, Buenos Aires, Paidós. Bourdieu, Pierre (1991): El sentido práctico, Madrid, Taurus.

-(1998): La domination masculine, París, Seuil.

Burin, M. y Meler, I. (1998): Género y familia. Poder, amor y sexualidad en la construcción de la subjetividad, Buenos Aires, Paidós.

-(2000): Varones. Género y subjetividad masculina, Buenos Aires, Paidós.

Castoriadis, Cornelius (1993): La institución imaginaria de la sociedad, Vol II: El imaginario social y la institución, Buenos Aires, Tusquets.

-(1992): El psicoanálisis. Proyecto y elucidación, Buenos Aires, Nueva Visión.

Chasseguet Smirgel, J. (1977): "La culpabilidad femenina" en La sexualidad femenina de Chasseguet Smirgel, J., (comp.) Barcelona, LAIA.

Chodorow, Nancy (1984): El ejercicio de la maternidad, Barcelona, Gedisa.

Deustch, Helène (1947): La psicología de la mujer, Buenos Aires, Losada.

Dio Bleichmar, Emilce (1985): El feminismo espontáneo de la histeria, Madrid, ADOTRAF.

Fernández, Ana María (1993): La mujer de la ilusión, Buenos Aires, Paidós.

Freud, Sigmund (1980): Obras Completas, Buenos Aires, Amorrortu. Incluye:

-(1905): Tres ensayos de teoría sexual.

-(1908): La moral sexual cultural y la nerviosidad moderna.

-(1909): Análisis de la fobia de un niño de cinco años (El pequeño Hans).

-(1910): Un recuerdo infantil de Leonardo da Vinci.

-(1912-13:) Tótem y Tabú.

-(1914): Introducción del narcisismo.

-(1919): Pegan a un niño. 
Psicoanálisis y género. Deconstrucción crítica de la teoría psicoanalítica...

—(1920): Más allá del principio de placer

-(1923): La organización genital infantil.

-(1924): El sepultamiento del complejo de Edipo.

-(1925): El problema económico del masoquismo.

-(1925): Algunas consecuencias psíquicas de la diferencia sexual anatómica.

-(1930): El malestar en la cultura.

-(1933): La femineidad.

-(1934): Moisés y la religión monoteísta.

-(1937): Análisis terminable e interminable.

Foucault, Michel (1980): Historia de la sexualidad, Tomo I: La voluntad de saber, Madrid, Siglo XXI, Tomo II: (1986) El uso de los placeres, México, Siglo XXI.

Gilligan, Carol (1985): La moral y la teoría, México, Fondo de cultura económica.

Horney, Karen (1982): "Sobre la génesis del complejo de castración en la mujer", en Psicología femenina, Madrid, Alianza Editorial.

Kohut, Heinz (1971): El análisis del Self, Buenos Aires, Amorrortu.

-(1977): La restauración del Self, Buenos Aires, Amorrortu.

Laplanche, Jean (1993): El extravío biologizante de la sexualidad en Freud, Buenos Aires, Amorrortu.

Levinton Dolman, Nora (2000): El superyo femenino. La moral en las mujeres, Madrid, Biblioteca Nueva.

Lipovetsky, Gilles (1999): La tercera mujer, Barcelona, Anagrama.

Mahler, Margaret (1972): Simbiosis humana. Las vicisitudes de la individuación, México, Joaquín Moritz.

Maldavsky, David (1980): El complejo de Edipo positivo. Constitución y transformaciones, Buenos Aires, Amorrortu.

Meler, Irene (1987): "Identidad de género y criterios de salud mental" en Mabel Burin et alii: Estudios sobre la subjetividad femenina. Mujeres y salud mental, Buenos Aires, GEL. 
—(1991): “La madre fálica: ¿un producto de la industria?” en Voces de femineidad de Mariam Alizade y Olga Salas (comps.) Buenos Aires, Fondo de Cultura Económica.

—(2000): “Creación cultural y masculinidad" en Burin, Mabel y Meler, Irene: Varones. Género y subjetividad masculina, Buenos Aires, Paidós.

—(1997): "Violencia entre los géneros. Cuestiones no pensadas o 'impensables", en Actualidad Psicológica, Buenos Aires.

-(2004): "Género y subjetividad: la construcción diferencial del Super-yo en mujeres y varones", Revista Subjetividad y Cultura No 21, México.

-(2005): "Violencia en las relaciones de género. Algunas hipótesis psicoanalíticas", en Actualidad Psicológica, Año XXIX, No 328, Buenos Aires.

-(2005): "El estatuto teórico del cuerpo en los estudios psicoanalíticos de género", Actualidad Psicológica, Año XXIX, No 335, Buenos Aires.

Moscovici, Serge (1985): Psicología Social, Barcelona, Paidós.

Rivière, Joan (1966): "La femineidad como máscara", en La sexualidad femenina, Buenos Aires, Caudex.

Roudinesco, Elizabeth y Plon, Michel (1998): Diccionario de Psicoanálisis, Buenos Aires, Paidós.

Stern, Daniel (1992): El mundo interpersonal del infante, Madrid, Paidós.

Winnicott, Donald (1985): Realidad y juego, Buenos Aires, Gedisa. 